\title{
Comparison of irinotecan and oxaliplatin as the first-line therapies for metastatic colorectal cancer: a meta-analysis
}

Sadayuki Kawai ${ }^{1,2^{*}}$ (D), Nozomi Takeshima ${ }^{3}$, Yu Hayasaka ${ }^{4}$, Akifumi Notsu ${ }^{5}$, Mutsumi Yamazaki ${ }^{6}$, Takanori Kawabata ${ }^{5}$, Kentaro Yamazaki ${ }^{1}$, Keita Mori ${ }^{5}$ and Hirofumi Yasui ${ }^{1}$

\begin{abstract}
Background: Irinotecan (IRI) and oxaliplatin (Ox) are standard therapeutic agents of the first-line treatments for metastatic colorectal cancer (mCRC). Previous meta-analyses of randomized controlled trials (RCTs) showed that treatment with Ox-based compared with IRI-based regimens was associated with better overall survival (OS). However, these reports did not include trials of molecular targeting agents and did not take methods for the administration of concomitant drugs, such as bolus or continuous infusion of 5-fluorouracil, into account. A systematic literature review was performed to compare the efficacy and toxicity profiles between IRI- and Ox-based regimens as the first-line treatments for $\mathrm{mCRC}$.

Methods: This meta-analysis used data from the Cochrane Central Register of Controlled Trials, PubMed, and SCOPUS. The primary endpoint was OS, and the secondary endpoints were progression-free survival (PFS), objective response rate (ORR), and adverse events (AEs).

Results: Nineteen trials involving 4571 patients were included in the analysis. No statistically significant difference was observed between the two groups in terms of OS, PFS, and ORR. There was no significant heterogeneity. Regarding $\geq$ grade 3 AEs, IRI-based regimens were associated with a high incidence of leukopenia, febrile neutropenia, and diarrhea. Moreover, there was a high incidence of thrombocytopenia and peripheral sensory neuropathy in patients who received Ox-based regimens. In a subgroup analysis, IRI combined with bevacizumab was correlated with a better PFS ( $H R=0.90,95 \% \mathrm{Cl}=0.82-0.98, P=0.02)$, but not with OS (pooled $H R=0.91,95 \%$ $\mathrm{Cl}=0.80-1.03, P=0.15)$.

Conclusion: Although the safety profiles of IRI- and Ox-based regimens varied, their efficacy did not significantly differ. The combination of anti-VEGF antibody and IRI was associated with better PFS compared with anti-VEGF antibody and Ox. Both regimens could be used as the first-line treatments for $\mathrm{mCRC}$ with consideration of the patients' condition or toxicity profiles.
\end{abstract}

Keywords: Meta-analysis, Metastatic colorectal cancer, Chemotherapy

\footnotetext{
* Correspondence: sadayuki-kawai@i.shizuoka-pho.jp

'Division of Gastrointestinal Oncology, Shizuoka Cancer Center, 1007

Shimonagakubo, Nagaizumi, Sunto-gun, Shizuoka 411-8777, Japan

${ }^{2}$ Department of Medical Oncology, Shizuoka General Hospital, 4-27-1 Kita ando, Aoi-ku, Shizuoka City 420-8527, Japan

Full list of author information is available at the end of the article
}

(c) The Author(s). 2021 Open Access This article is licensed under a Creative Commons Attribution 4.0 International License, which permits use, sharing, adaptation, distribution and reproduction in any medium or format, as long as you give appropriate credit to the original author(s) and the source, provide a link to the Creative Commons licence, and indicate if changes were made. The images or other third party material in this article are included in the article's Creative Commons. licence, unless indicated otherwise in a credit line to the material. If material is not included in the article's Creative Commons licence and your intended use is not permitted by statutory regulation or exceeds the permitted use, you will need to obtain permission directly from the copyright holder. To view a copy of this licence, visit http://creativecommons.org/licenses/by/4.0/ The Creative Commons Public Domain Dedication waiver (http://creativecommons.org/publicdomain/zero/1.0/) applies to the data made available in this article, unless otherwise stated in a credit line to the data. 


\section{Background}

Currently, colorectal cancer (CRC) ranks fourth for incidence worldwide, with 550,000 deaths recorded annually [1]. Patients with unresectable metastatic CRC (mCRC) have a poor prognosis, with a median overall survival (OS) of 6-8 months, without any therapy. Although chemotherapy is the standard treatment for these patients, the median OS is only 20-25 months [2].

The combination of cytotoxic and molecular targeting agents is currently used as the first-line treatment for patients with unresectable mCRC. Irinotecan (IRI) or oxaliplatin $(\mathrm{Ox})$ combined with fluoropyrimidines (FPs) is considered as the backbone of cytotoxic agents for the treatment of $\mathrm{mCRC}$ [3]. In the meta-analysis conducted by Grothey et al. [4], the use of all three active drugs (FPs, IRI, and $\mathrm{Ox}$ ) for $\mathrm{mCRC}$ was associated with a long OS.

First-line treatment is important for patients with mCRC, because the treatment period is the longest of the overall treatment time and significantly affects survival and quality of life (QOL). With regard to the use of cytotoxic agents, several trials investigated the best combination of regimens. Tournigand et al. [5] and Colucci et al. [6] conducted clinical trials to compare the efficacy between 5-fluorouracil (5-FU), folinic acid, and $\mathrm{Ox}$ (FOLFOX) regimen and 5-FU, folinic acid, and IRI (FOLFIRI) regimen. Results showed no significant differences between the two regimens. Moreover, Yamazaki et al. [7] compared these regimens with bevacizumab (BEV), a molecular targeting agent. Results showed that the OS did not significantly differ between patients who received FOLFOX + BEV and FOLFIRI + BEV. Hence, both IRI- and Ox-based regimens could be used as the first-line treatments for mCRC.

In clinical practice, physicians generally select the regimen based on adverse events (AEs) caused by the drugs or the patients' condition. Recent reports showed that physicians preferred Ox-based regimen than IRI-based regimen. Field et al. [8] conducted a survey on the use of chemotherapy for CRC. Results showed that 92.6\% of medical oncologists in Australia select Ox-based regimen as the first-line treatment. They reported physicians commonly select this regimen as it has better efficacy and lower toxicity than IRI-based regimen. In addition, Marschner et al. [9] conducted a prospective cohort study and revealed that $\mathrm{Ox}$-based regimen was used as the first-line treatment in 430 out of 605 patients (71.0\%) with mCRC.

Previous meta-analyses [10-12] of the first-line treatments for $\mathrm{mCRC}$ revealed that Ox-based regimen was correlated with a better OS. However, these studies included trials comparing continuous 5 -FU infusion regimen with bolus 5-FU regimen, which is currently considered an inferior method. Moreover, these data were obtained from reports of regimens without molecular targeting agents. Therefore, they might not be applicable in the current clinical practice. Recently, a population-based observational study conducted by Teng et al. [13] reported that IRI-based regimen might be more effective in improving OS than Ox-based regimen. Therefore, it remains unclear which regimen is associated with a better OS. Thus, a meta-analysis based on the current knowledge was performed to compare the efficacy and toxicity between IRI- and Ox-based regimens as the first-line treatments for mCRC.

\section{Methods}

\section{Search strategy and selection criteria}

We searched PubMed, SCOPUS, and the Central Registry of Controlled Trials of the Cochrane Library (CENT RAL) without language restrictions. The last search update was performed on December 17, 2018. The inclusion criteria were as follows: (1) randomized controlled trials comparing IRI- and Ox-based combination regimens as the first-line treatments for mCRC and (2) those using similar agents (IRI- or Ox-based combination regimens) or agents with comparable efficacy based on the results of previous randomized controlled trials. The efficacy of oral FPs was similar to that of continuous infusion of 5-FU. That is, capecitabine $+\mathrm{Ox}$ $(\mathrm{CapOx})$ regimen and $\mathrm{S}-1+\mathrm{Ox}(\mathrm{SOX})$ regimen were considered as alternative to FOLFOX regimen [14-16]. Similarly, capecitabine + IRI (CapIRI) and S-1 + IRI (IRIS) regimens were considered as alternative to FOLFIRI regimen [17, 18]. (3) Abstracts or unpublished data were included if they had sufficient information on study design, characteristics of participants, interventions, and outcomes.

The search terms used were as follows: (1) terms suggestive of "colorectal" (i.e., "colorect", "colon," "colonic," "bowel"," "recta"," or "rectum"), (2) "cancer" (i.e., "cancer," "carcinoma"," "neoplas"," or "tumor"), (3) "irinotecan" (i.e., "irinotecan," "camptotecin-11," or "topotecin"), (4) "oxaliplatin" (i.e., "L-OHP," "eloxatine," or "oxaliplatin"), and (5) "randomized trials" (i.e., "ramdomized controlled,","randomised," or "randomly").

\section{Data extraction}

At least two of three review authors (SK, NT, and $\mathrm{YH}$ ) independently scanned titles and abstracts to exclude studies that do not meet the criteria. The full text reports were then reviewed for further assessment. Disagreements were resolved via a consensus. Detailed data from eligible trials, such as year of publication, place where the study was conducted, study design, regimens, participants' information, methodological evaluation, outcomes, and AEs, were extracted. If necessary, the authors were contacted for clarifications. 


\section{Assessment of risk of Bias}

At least two of three authors (SK, NT, and YH) independently assessed the risk of bias in the included studies in accordance with the Cochrane Handbook for Systematic Reviews of Interventions [19]. The following domains were assessed: (1) sequence generation; (2) allocation concealment; (3) blinding of participants, personnel, and outcome assessors; (4) incomplete outcome data; (5) selective outcome reporting; and (6) other potential threats to validity. When inadequate details of methodological characteristics of trials were provided, the authors were contacted to obtain further information.

\section{Statistical analysis}

The primary endpoint was OS. The secondary endpoints were progression-free survival (PFS), objective response rate (ORR), and $\geq$ grade $3 \mathrm{AEs}$ according to the Common Terminology Criteria for Adverse Events version 4.0. Hazard ratios (HRs) and $95 \%$ confidence interval (CI), which were considered as relevant effect measures, were directly or indirectly assessed using the given data. When the Kaplan-Meier curve, but not the HR for PFS or OS, was included, we extracted the value using the Engauge Digitizer 10.8 and the method provided by Tierney et al. [20] ORR were compared using odds ratio (OR). The risk difference was used to compare the risk of AEs. Statistical heterogeneity among the studies was assessed using the chi-square test and was expressed with the $I^{2}$ index [19]. The pooled effect was calculated with the random-effects model. Subgroup analyses were performed according to the combination of agents, which include regimens with or without molecular targeting agents, infusion of 5-FU or oral FPs, and antiepidermal growth factor receptor (EGFR) or anti-ca (VEGF) antibodies. Since a previous report showed that CapOx plus anti-EGFR antibody might be less effective than FOLFOX plus anti-EGFR [21], we added the subgroup of anti-EGFR antibodies except CapOx + cetuximab. Statistical analyses were performed using the RevMan 5.3 software, which was provided by The Cochrane Collaboration. The corresponding funnel plots were used to examine the effect of publication bias visually. A two-sided $P$-value $<0.05$ was considered statistically significant. This study was not registered in any registry although we followed a protocol designed for it.

\section{Results}

Search results and characteristics of the included trials A total of 4451 potentially relevant studies were retrieved from the initial database search in PubMed, SCOPUS, and CENTRAL. Of these studies, 22 met all the inclusion criteria. However, one trial did not provide sufficient data [22], and two were discontinued early due to poor accrual $[23,24]$. Finally, 19 RCTs [5-7, 25-40] with 4571 patients were included in the analysis. A flowchart of the search process is shown in Fig. 1.

Table 1 shows the characteristics of RCTs included in the meta-analysis. Of these, 12 trials $(n=3534)$ used 5FU infusion regimens; $6(n=943)$, oral FPs; and 1 ,

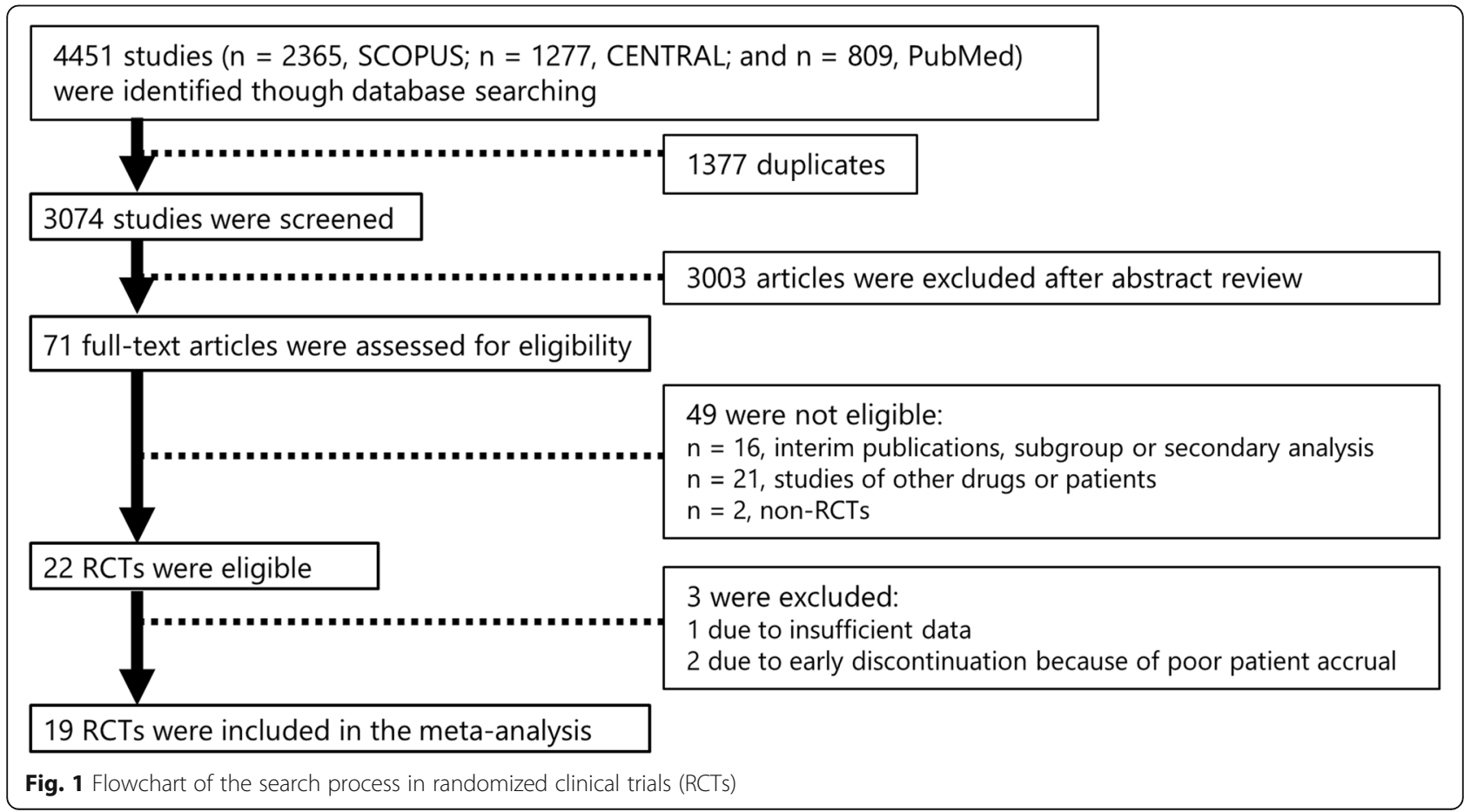


Table 1 Characteristics of randomized controlled trials included in the meta-analysis

\begin{tabular}{|c|c|c|c|c|c|c|c|c|}
\hline Study no. & Authors & Region & Year & Trial phase & Primary endpoint & Interventions & Patients & Median OS (months) \\
\hline 1 & Grothey et al. [25] & USA & 2003 & 2 & AEs & $\begin{array}{l}\text { CapOx } \\
\text { CaplRI }\end{array}$ & $\begin{array}{l}82 \\
79\end{array}$ & $\begin{array}{l}\text { NA } \\
\text { NA }\end{array}$ \\
\hline 2 & Tournigand et al. [5] & France & 2004 & 3 & PFS & $\begin{array}{l}\text { FOLFOX } \\
\text { FOLFIRI }\end{array}$ & $\begin{array}{l}113 \\
113\end{array}$ & $\begin{array}{l}20.6 \\
21.5\end{array}$ \\
\hline 3 & Kalofonos et al. [26] & Greece & 2005 & 2 & ORR & $\begin{array}{l}\text { Weekly Ox + LV + 5-FU } \\
\text { Weekly IRI + LV + 5-FU }\end{array}$ & $\begin{array}{l}148 \\
147\end{array}$ & $\begin{array}{l}17.4 \\
17.6\end{array}$ \\
\hline 4 & Comella et al. [27] & Italy & 2005 & 3 & ORR & $\begin{array}{l}\text { OXAFAFU } \\
\text { IRIFAFU }\end{array}$ & $\begin{array}{l}140 \\
133\end{array}$ & $\begin{array}{l}18.9 \\
15.6\end{array}$ \\
\hline 5 & Colucci et al. [6] & Italy & 2005 & 3 & ORR & $\begin{array}{l}\text { FOLFOX } \\
\text { FOLFIRI }\end{array}$ & $\begin{array}{l}182 \\
178\end{array}$ & $\begin{array}{l}15 \\
14\end{array}$ \\
\hline 6 & Feliu et al. [28] & Spain & 2005 & 2 & ORR & $\begin{array}{l}\text { Raltitrexed + Ox } \\
\text { Raltitrexed + IRI }\end{array}$ & $\begin{array}{l}48 \\
46\end{array}$ & $\begin{array}{l}\text { NA } \\
\text { NA }\end{array}$ \\
\hline 7 & Zheng et al. [29] & China & 2006 & 2 & ORR & $\begin{array}{l}\text { FOLFOX7 } \\
\text { FOLFIRI }\end{array}$ & $\begin{array}{l}30 \\
30\end{array}$ & $\begin{array}{l}\text { NA } \\
\text { NA }\end{array}$ \\
\hline 8 & Bajetta et al. [30] & Italy & 2007 & 2 & AEs & $\begin{array}{l}\text { TEGAFOX } \\
\text { TEGAFIRI }\end{array}$ & $\begin{array}{l}73 \\
68\end{array}$ & $\begin{array}{l}19 \\
20\end{array}$ \\
\hline 9 & Seymour et al. [31] & UK & 2007 & 3 & OS & $\begin{array}{l}\text { OxFU } \\
\text { IrFU }\end{array}$ & $\begin{array}{l}357 \\
356\end{array}$ & $\begin{array}{l}15.4 \\
16.7\end{array}$ \\
\hline 10 & Rosati et al. [32] & Italy & 2010 & 2 & ORR & $\begin{array}{l}\text { CapOx } \\
\text { CaplRI }\end{array}$ & $\begin{array}{l}47 \\
47\end{array}$ & $\begin{array}{l}19.3 \\
14\end{array}$ \\
\hline 11 & Ocvirk et al. [33] & $\begin{array}{l}\text { Germany } \\
\text { Austria }\end{array}$ & 2010 & 2 & PFS & $\begin{array}{l}\text { FOLFOX6 + Cmab } \\
\text { FOLFIRI }+ \text { Cmab }\end{array}$ & $\begin{array}{l}77 \\
74\end{array}$ & $\begin{array}{l}17.4 \\
18.9\end{array}$ \\
\hline 12 & Moosmann et al. [34] & Germany & 2011 & 2 & ORR & $\begin{array}{l}\text { CapOx + Cmab } \\
\text { CaplRI + Cmab }\end{array}$ & $\begin{array}{l}92 \\
93\end{array}$ & $\begin{array}{l}25.5 \\
21.1\end{array}$ \\
\hline 13 & Schmiegel et al. [35] & Germany & 2013 & 2 & PFS & $\begin{array}{l}\text { CapOx + BEV } \\
\text { CapIRI + BEV }\end{array}$ & $\begin{array}{l}127 \\
128\end{array}$ & $\begin{array}{l}24.4 \\
25.5\end{array}$ \\
\hline 14 & Folprecht et al. [36] & $\begin{array}{l}\text { Germany } \\
\text { Austria }\end{array}$ & 2014 & 2 & ORR & $\begin{array}{l}\text { FOLFOX6 + Cmab } \\
\text { FOLFIRI }+ \text { Cmab }\end{array}$ & $\begin{array}{l}56 \\
55\end{array}$ & $\begin{array}{l}35.8 \\
29\end{array}$ \\
\hline 15 & Yamazaki et al. [7] & Japan & 2016 & 3 & PFS & $\begin{array}{l}\text { FOLFOX6 + BEV } \\
\text { FOLFIRI + BEV }\end{array}$ & $\begin{array}{l}200 \\
202\end{array}$ & $\begin{array}{l}30.4 \\
31.4\end{array}$ \\
\hline 16 & Parikh et al. [37] & USA & 2018 & 2 & PFS & $\begin{array}{l}\text { FOLFOX6 + BEV } \\
\text { FOLFIRI + BEV }\end{array}$ & $\begin{array}{l}188 \\
188\end{array}$ & $\begin{array}{l}23.9 \\
27.5\end{array}$ \\
\hline 17 & Carrato et al. [38] & Spain & 2017 & 2 & ORR & $\begin{array}{l}\text { FOLFOX4 + Pmab } \\
\text { FOLFIRI + Pmab }\end{array}$ & $\begin{array}{l}40 \\
40\end{array}$ & $\begin{array}{l}37 \\
41\end{array}$ \\
\hline 18 & Yamada et al. [39] & Japan & 2018 & 3 & PFS & $\begin{array}{l}\text { FOLFOX (CapOX) + BEV } \\
\text { S-1 + IRI + BEV }\end{array}$ & $\begin{array}{l}244 \\
243\end{array}$ & $\begin{array}{l}33.6 \\
34.8\end{array}$ \\
\hline 19 & Nakayama et al. [40] & Japan & 2018 & 2 & ORR & $\begin{array}{l}\text { CapOx + BEV } \\
\text { CapIRI + BEV }\end{array}$ & $\begin{array}{l}54 \\
53\end{array}$ & $\begin{array}{l}26.7 \\
28.7\end{array}$ \\
\hline
\end{tabular}

OS overall survival, $A E s$ adverse events, $P F S$ progression-free survival, ORR objective response rate, NA not available, CapOx capecitabine + Ox, CapIRI capecitabine + IRI, FOLFOX and OXAFAFU 5-FU + folinic acid + Ox, FOLFIRI and IRIFAFU 5-FU + folinic acid + IRI, TEGAFOX tegafur + folinic acid + Ox, TEGAFIRI tegafur + folinic acid + IRI, BEV bevacizumab, Cmab cetuximab, Pmab panitumumab

raltitrexed $(n=94)$. Nine RCTs $(n=2154)$ used regimens with molecular targeting agents. Among them, five used BEV and four anti-EGFR antibodies (cetuximab or panitumumab). In total, 2 RCTs were conducted in North America, 13 in Europe, and 4 in Asia. The median age of the participants in all studies was $61-75$ years. In one trial [32], only elderly patient aged $>70$ years was eligible.

\section{Efficacy and toxicity}

Sixteen trials included data on OS (Fig. 2a). Since seven RCTs did not describe the HR for OS, we estimated the value using the Kaplan-Meier curve. Results showed no significant difference between IRI- and Ox-based regimens (pooled HR $=0.96,95 \% \mathrm{CI}=0.89-1.03, P=0.28$ ), and there was no significant heterogeneity among the trials $\left(I^{2}=2 \%\right)$. Thirteen trials included data on PFS (Fig. 2b). We estimated the HR for PFS in six trials using the Kaplan-Meier curve. No significant difference was observed between the two groups (pooled $\mathrm{HR}=0.98,95 \%$ $\mathrm{CI}=0.94-1.04, P=0.49)$, and there was no significant heterogeneity $\left(I^{2}=0 \%\right)$. All trials included data on ORR (Fig. 2c). There was no significant difference between the two groups. However, Ox-based regimen had a 


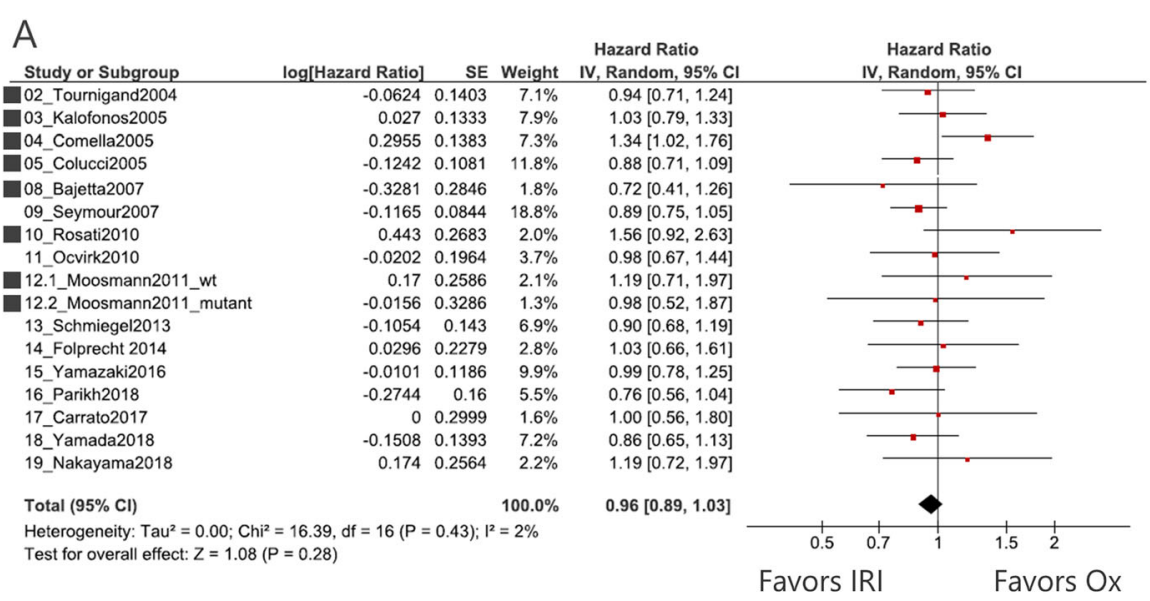

B

\begin{tabular}{|c|c|c|c|}
\hline Study or Subgroup & log[Hazard Ratio] & SE & Weight \\
\hline 03_Kalofonos2005 & 0.0449 & 0.1124 & $9.4 \%$ \\
\hline 04_Comella2005 & 0.1096 & 0.1089 & $10.0 \%$ \\
\hline $\begin{array}{l}05 \text { Colucci2005 } \\
10 \text { Rosati2010 }\end{array}$ & $\begin{array}{l}0.0314 \\
0.3825\end{array}$ & $\begin{array}{l}0.0985 \\
0.2487\end{array}$ & $\begin{array}{r}12.2 \% \\
1.9 \%\end{array}$ \\
\hline 11_Ocvirk2010 & 0.0583 & 0.1839 & $3.5 \%$ \\
\hline 12.1_Moosmann2011_wt & 0.1254 & 0.1941 & $3.1 \%$ \\
\hline 12.2 Moosmann2011 mutant & 0.0682 & 0.2883 & $1.4 \%$ \\
\hline 13_Schmiegel2013 & -0.0726 & 0.0715 & $23.2 \%$ \\
\hline 14_Folprecht 2014 & 0.1655 & 0.2047 & $2.8 \%$ \\
\hline 15_Yamazaki2016 & -0.0998 & 0.1146 & $9.0 \%$ \\
\hline 16 Parikh2018 & -0.2357 & 0.1319 & $6.8 \%$ \\
\hline 17_Carrato2017 & -0.1054 & 0.2606 & $1.7 \%$ \\
\hline 18_Yamada2018 & -0.1744 & 0.0991 & $12.1 \%$ \\
\hline 19_Nakayama2018 & 0.1222 & 0.2091 & $2.7 \%$ \\
\hline Total $(95 \% \mathrm{Cl})$ & & & $100.0 \%$ \\
\hline
\end{tabular}

Hazard Ratio , Random, $95 \% \mathrm{Cl}$ $1.05[0.84,1.30]$ $1.12[0.90,1.38]$ $1.03[0.85,1.25]$ $1.47[0.90,2.39]$ $1.06[0.74,1.52]$ $1.13[0.77,1.66]$ $1.07[0.61,1.88]$ $0.93[0.81,1.07]$ $1.18[0.79,1.76]$ $0.91[0.72,1.13]$ $0.79[0.61,1.02]$ $0.90[0.54,1.50]$ $0.90[0.54,1.50]$ $0.84[0.69,1.02]$
$1.13[0.75,1.70]$

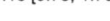
$0.98[0.91,1.04]$ Test for overall effect: $Z=0.68(P=0.49)$

Hazard Ratio

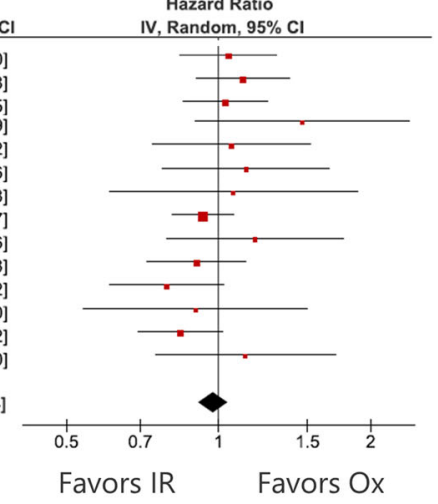

C

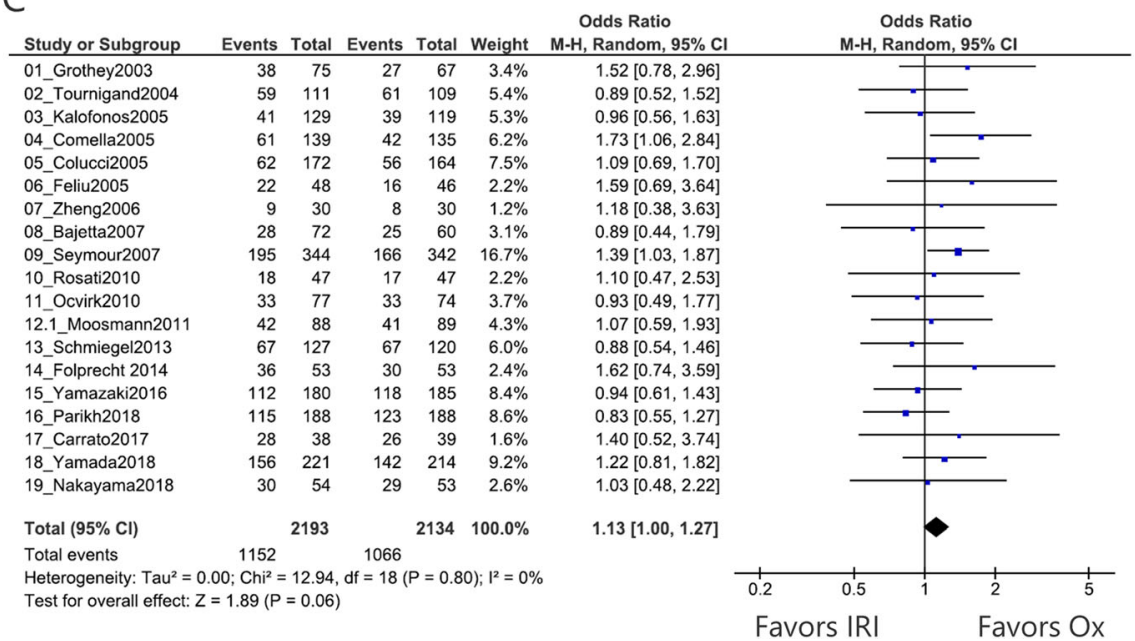

Fig. 2 Pooled analyses of each endpoint. Black dot at the left side represents the estimated hazard ratio obtained using the Kaplan-Meier curve. a Pooled analysis of overall survival (OS). b Pooled analysis of progression-free survival (PFS). c Pooled analysis of objective response rate (ORR). IRI, irinotecan; Ox, oxaliplatin; and $\mathrm{Cl}$, confidence interval

favorable outcome (pooled $\mathrm{OR}=1.13,95 \% \mathrm{CI}=1.00$ $1.27, P=0.06)$. No significant heterogeneity was observed $\left(I^{2}=0 \%\right)$.

We then performed a subgroup analysis according to the combination regimens. Overall, the OS did not significantly differ between IRI- and Ox-based regimens in all subgroups (Fig. 3a). The combined therapy of IRI and anti-VEGF was associated with a better PFS (pooled $\mathrm{HR}=0.90,95 \% \mathrm{CI}=0.82-0.98, P=0.02$ ), but not with OS (pooled $\mathrm{HR}=0.91,95 \% \mathrm{CI}=0.80-1.03, \quad P=0.15$ ) 
A

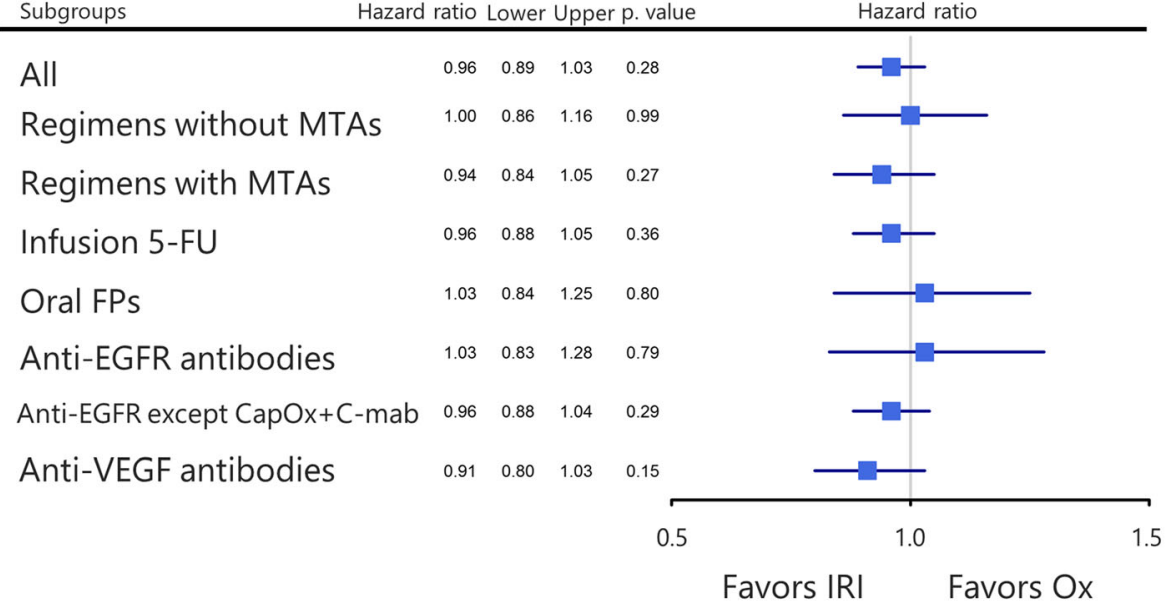

B

\begin{tabular}{|c|c|c|c|c|c|c|}
\hline Subgroups & ratio $L$ & ower & Upper & p. value & Hazard ratio & \\
\hline All & 0.98 & 0.91 & 1.04 & 0.49 & & \\
\hline Regimens without MTAs & 1.08 & 0.96 & 1.22 & 0.19 & & \\
\hline Regimens with MTAs & 0.93 & 0.85 & 1.01 & 0.08 & & \\
\hline Infusion 5-FU & 1.00 & 0.91 & 1.09 & 0.96 & & \\
\hline Oral FPs & 1.01 & 0.88 & 1.15 & 0.38 & & \\
\hline Anti-EGFR antibodies & 1.08 & 0.89 & 1.31 & 0.42 & & \\
\hline Anti-EGFR except CapOx+C-mab & 0.97 & 0.90 & 1.05 & 0.49 & & \\
\hline \multirow[t]{2}{*}{ Anti-VEGF antibodies } & 0.90 & 0.82 & 0.98 & 0.02 & - & \\
\hline & & & & 0.5 & 1.0 & 1.5 \\
\hline
\end{tabular}

C

\begin{tabular}{|c|c|c|c|c|c|c|}
\hline Subgroups & & ower & Uppe & p. value & dds ratio & \\
\hline All & 1.13 & 1.00 & 1.27 & 0.06 & & \\
\hline Regimens without MTAs & 1.22 & 1.03 & 1.45 & 0.02 & & \\
\hline Regimens with MTAs & 1.02 & 0.85 & 1.22 & 0.86 & & \\
\hline Infusion 5-FU & 1.13 & 0.97 & 1.31 & 0.11 & & \\
\hline Oral FPs & 1.04 & 0.8 & 1.36 & 0.76 & & \\
\hline Anti-EGFR antibodies & 1.16 & 0.81 & 1.65 & 0.43 & & \\
\hline Anti-EGFR except CapOx+C-mab & 1.12 & 0.99 & 1.27 & 0.08 & & \\
\hline \multirow[t]{2}{*}{ Anti-VEGF antibodies } & 0.97 & 0.79 & 1.2 & 0.79 & & \\
\hline & & & & 0.5 & 1.0 & 1.5 \\
\hline
\end{tabular}

Fig. 3 Subgroup analyses according to combination regimens. a Pooled analysis of overall survival (OS). b Pooled analysis of progression-free survival (PFS). c Pooled analysis of objective response rate (ORR). IRI, irinotecan; Ox, oxaliplatin; MTAs, molecular targeting agents; CapOx, capecitabine plus oxaliplatin; C-mab, cetuximab; 5-FU, 5-fluorouracil; FPs, fluoropyrimidines; EGFR, epidermal growth factor receptor; and VEGF, vascular endothelial growth factor 
compared with Ox and anti-VEGF combination (Fig. 3b and a). Ox-based regimens, especially those without molecular targeting agents, were associated with a better ORR (pooled $\mathrm{OR}=1.22,95 \% \mathrm{CI}=1.03-1.45, \quad P=0.02$ ) (Fig. 3c).

The incidence of any $\geq$ grade 3 AEs did not significantly differ between patients who received the two regimens. Thrombocytopenia, peripheral sensory neuropathy, hand-foot syndrome, and allergic reaction were significantly correlated with Ox-based regimens. Meanwhile, leukopenia, diarrhea, and febrile neutropenia were commonly observed in patients who received IRIbased regimens (Fig. 4).

\section{Assessment of risk of Bias}

Risk of bias assessment is shown in Fig. 5. Overall, the quality of evidence in this study was moderate according to the risk of bias assessment (Fig. 5a). The funnel plot of each effect size in terms of OS, PFS, and ORR was symmetrical, with a similar number of studies on either side of the summary treatment effect. This result indicated a lack of major publication bias (Fig. 5b).

\section{Discussion}

Based on the current expert panels of guidelines [3, 41, 42], there is no preferred regimen that can be used as the initial therapy for mCRC. Hence, IRI- or Ox-based regimen can be an alternative. In clinical practice, the regimen is selected based on efficacy of the regimens, physicians' experience, and profiles of AEs.

Our analysis showed that there was no significant difference in terms of OS between patients who received IRI- and Ox-based regimens as the first-line treatments for mCRC. This is the first meta-analysis that included treatments containing molecular targeting agents and clinically comparable combination of regimens. Therefore, the results of this study may be more applicable to current clinical practice than those of previous studies. The absence of significant heterogeneity between trials in terms of OS, PFS, and ORR indicated consistent results. Previous reports [10-12] showed that Ox-based regimen was more preferred in terms of OS. This discrepancy in results may be attributed to the selection criteria of the trials. That is, previous studies included trials comparing FOLFOX with IFL (bolus 5-FU + IRI) regimen [43, 44]. However, Delaunoit et al. [45] showed that bolus 5-FU + IRI or Ox could be associated with

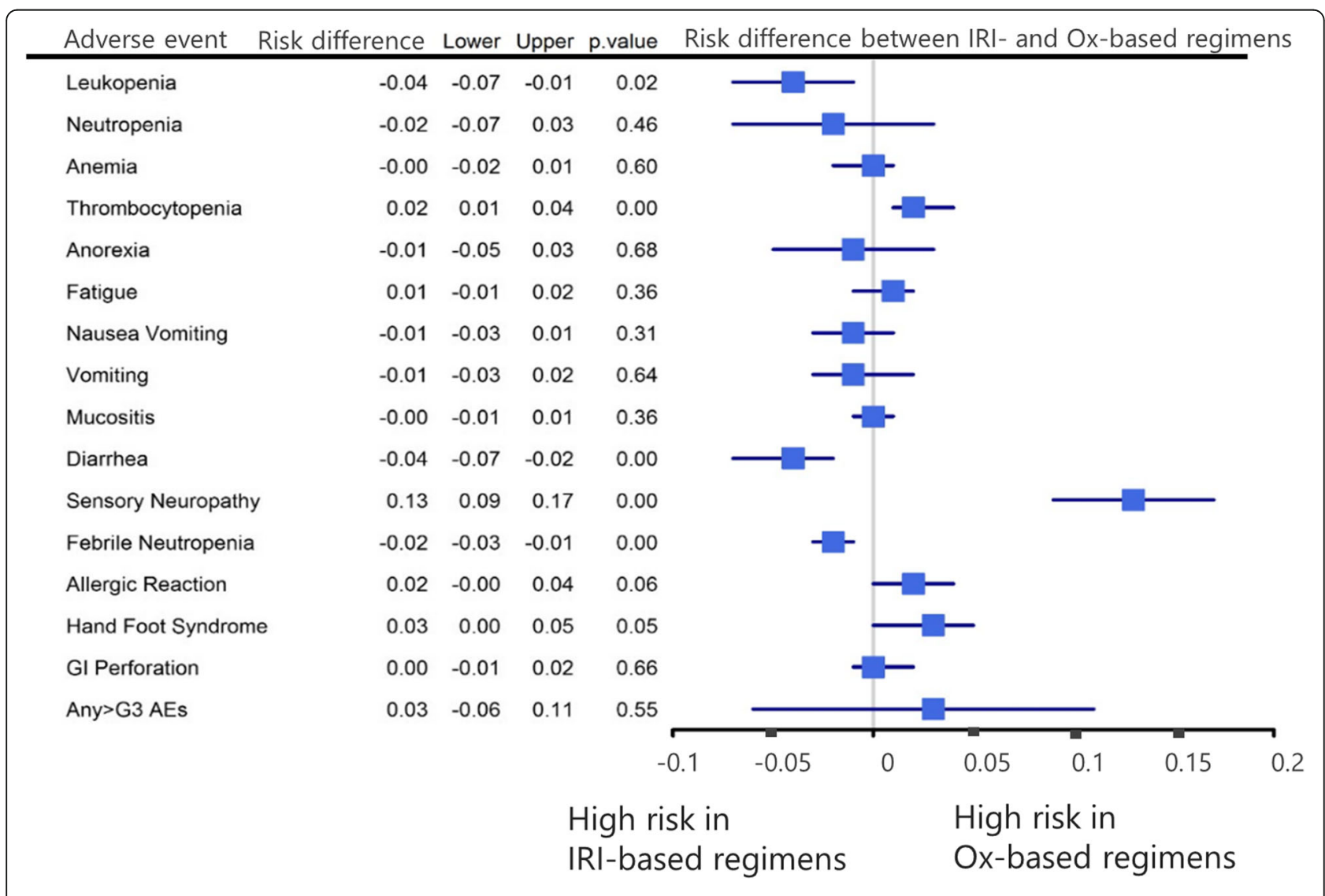

Fig. 4 Risk difference in the incidence of $\geq$ grade 3 AEs between patients who received IRI- and Ox-based regimens. IRI, irinotecan; Ox, oxaliplatin 
A

Sequence generation (SQ)

Allocation concealment $(A L)$

Blinding ( $\mathrm{BL})$

Incomplete outcome data (IN)

Selective outcome reporting (SL)

Other potential threats to validity (OT)

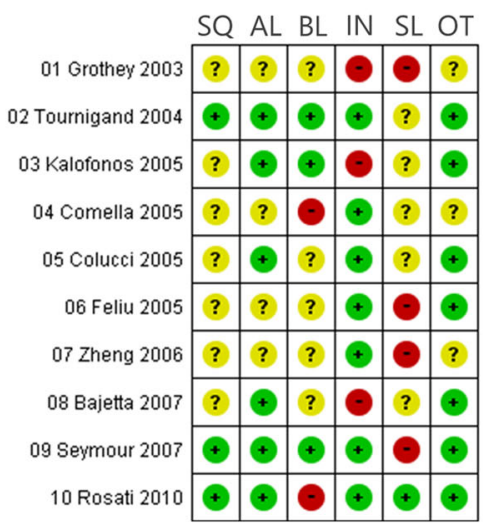

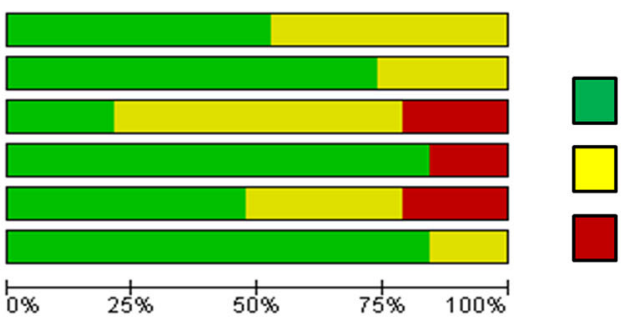

Low risk of bias

Unclear risk of bias

High risk of bias

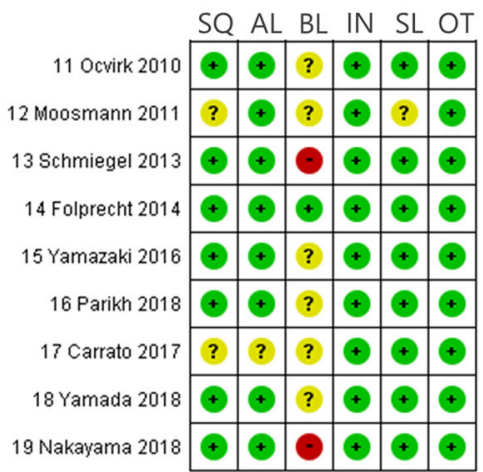

B
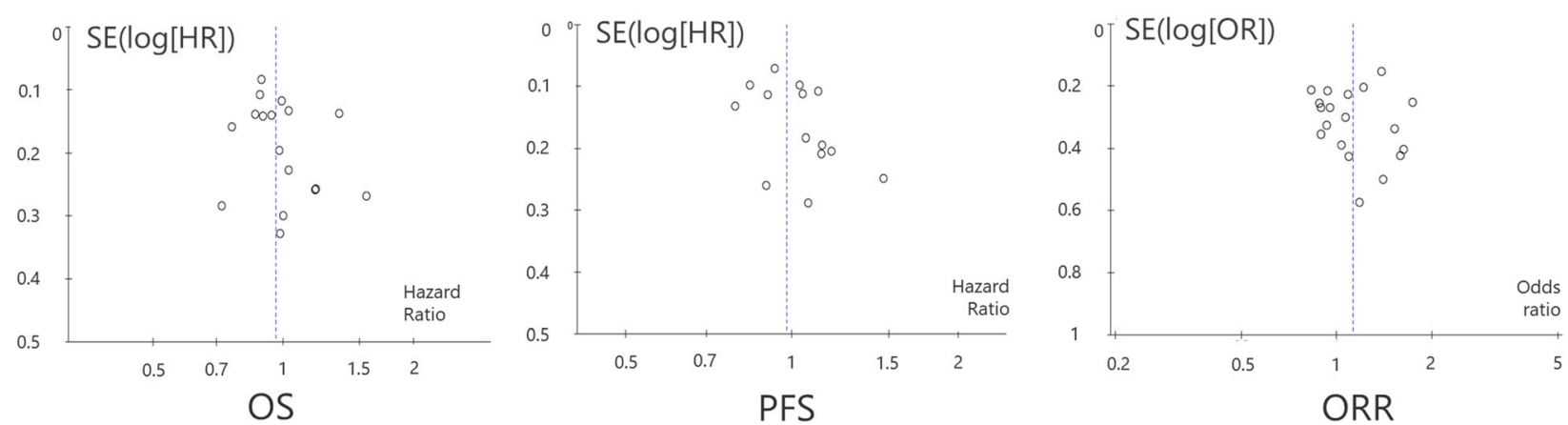

Fig. 5 Assessment of risk of bias. a Risk of bias assessment for each included RCT. The bar chart indicates the distribution of risk-of-bias judgments across the domains. b The funnel plot of each effect size in terms of overall survival (OS), progression-free survival (PFS), and objective response rate $(\mathrm{ORR})$. SQ, sequence generation; $\mathrm{AL}$, allocation concealment; $\mathrm{BL}$, blinding; IN, incomplete outcome data; $\mathrm{SL}$, selective outcome reporting; OT, other potential threats to validity; SE, standard error; HR, hazard ratio; OR, odds ratio

severe gastrointestinal toxicity and high mortality rates. Thus, excluding these trials was appropriate for the evaluation of efficacy and toxicity between the two regimens.

In the subgroup analysis of regimens without molecular targeting agents, Ox-based regimen was associated with a better ORR. However, the PFS and OS did not significantly differ. In colorectal cancer, the correlation between ORR and OS is not clearly elucidated [46]. Hence, our results were not conflicting. In addition, in this subgroup, six of ten trials [6, 26-29, 32] used ORR as the primary endpoint, and four $[6,27,29,32]$ studies hypothesized that Ox-based regimen is associated with a better ORR. Thus, the evaluation of ORR might be biased in these trials.

In the subgroup analysis of regimens with molecular targeting agents, the combination of anti-VEGF antibody and IRI was more likely to be associated with better PFS and OS. Ren et al. [47] reported same results in their meta-analysis including RCT and observational studies. Previous studies $[48,49]$ suggested that SN38, an active metabolite of IRI, had multiple anti-angiogenic effect through inhibition of VEGF production via inhibition of HIF- $1 \alpha$ and a direct effect on endothelial cells. Thus, anti-VEGF antibody and IRI might work synergistically. As a growing number of active compounds have become 
available as second- or subsequent line chemotherapy for colorectal cancer in recent years, we speculated that prolonged PFS might not directly lead to significantly longer OS.

With regard to the results of AEs, though details of each $\mathrm{AE}$ was different from each other, the incidence of any $\geq$ grade 3 AEs did not significantly differ between patients who received the two regimens. Therefore, it may be reasonable for physicians to select each regimen according to AE profiles. However, previous systematic reviews including any grade of $\mathrm{AE}[12,47]$ reported that the number of incidence of nausea/vomiting and mucositis are more observed in IRI-based regimens without molecular targeting agents than $\mathrm{Ox}$, and bleeding event and venous thromboembolism are more observed in IRI + anti-VEGF regimens compared with $\mathrm{Ox}+$ anti-VEGF. Thus combination agents may affect the toxicity profile. Yamazaki et al. [7] revealed that the FACT-C OQL score was more likely worse in patients treated with FOLFOX + BEV than in those treated with FOLFIRI + BEV. Moreover, a previous report indicated that peripheral sensory neuropathy lasts for a long period and affects QOL after treatment [50]. Thus, physicians should consider QOL during not only the first-line treatment but also the overall survival time when selecting the regimens.

This study had some limitations. That is, it is a metaanalysis. Moreover, there were no data on race, sex, primary site of the tumor, and status of RAS and BRAF genes. Thus, our data must be applied with caution to individual patients in clinical practice. Recently, some reports showed that the molecular subtypes or chromosomal variation of CRC might affect the efficacy of IRIand Ox-based regimens [51, 52]. Thus, in the future, suitable cytotoxic agents should be selected according to biomarker profile.

\section{Conclusions}

The efficacy of IRI- and Ox-based regimens when used as the first-line treatments for mCRC did not significantly differ. In subgroup analysis, the combination of anti-VEGF antibody and IRI was associated with better PFS. Both regimens could be used in clinical practice with consideration of the patients' condition or toxicity profiles.

\footnotetext{
Abbreviations

IRI: Irinotecan; Ox: Oxaliplatin; mCRC: Metastatic colorectal cancer; RCT: Randomized controlled trial; OS: Overall survival; PFS: Progression free survival; ORR: Objective response rate; AEs: Adverse events; HR: Hazard ratio; FPs: Fluoropyrimidines; QOL: Quality of life; CENTRAL: The Central Registry of Controlled Trials of the Cochrane Library; Cl: Confidence interval; EGFR: Epidermal growth factor receptor; VEGF: Vascular endothelial growth factor; CapOx: Capecitabine + oxaliplatin; CapIRI: Capecitabine + irinotecan; IFL: Bolus 5-FU + irinotecan; 5-FU: 5-fluorouracil; BEV: Bevacizumab; IRIS: S-1 + irinotecan, FOLFOX and OXAFAFU, 5-FU + folinic acid + oxaliplatin; FOLFIRI and IRIFAFU: 5-FU + folinic acid + irinotecan; TEGAFOX: Tegafur + folinic acid
}

+ oxaliplatin; TEGAFIRI: Tegafur + folinic acid + irinotecan; NA: Not available; MTAs: Molecular targeting agents

\section{Acknowledgements}

We would like to show our greatest appreciation to Dr. Goro Nakayama and Dr. Gerardo Rosati for providing data of their clinical trials.

\section{Authors' contributions}

Conceptualization and study design: SK, NT, YH, KY, AN, TK, KM, MY; Writing an original draft: SK; Project administration: YH, KY; Review and editing: SK, NT, YH, AN, MY, TK, KM, KY; Formal analysis: AN, TK, KM; Supervision: YH, KM, KY; Investigation of data: SK, NT, YH, MY; and All authors read and approved the final manuscript.

\section{Funding}

The authors have not declared a specific grant for this research from any funding agency in the public, commercial or not-for-profit sectors.

\section{Availability of data and materials}

The datasets used and/or analyzed during the current study are available from the corresponding author on reasonable request.

\section{Ethics approval and consent to participate}

Not applicable. Ethical approval was not required for this study because this meta-analysis is literature based research and did not use individual data.

\section{Consent for publication}

Not applicable.

\section{Competing interests}

All authors declare no conflicts-of-interest related to this article.

\section{Author details}

${ }^{1}$ Division of Gastrointestinal Oncology, Shizuoka Cancer Center, 1007 Shimonagakubo, Nagaizumi, Sunto-gun, Shizuoka 411-8777, Japan. 2Department of Medical Oncology, Shizuoka General Hospital, 4-27-1 Kita ando, Aoi-ku, Shizuoka City 420-8527, Japan. ${ }^{3}$ Department of Psychiatry, Kitabayashi Hospital, 7-58 Nakamura-cho, Nakamura-ku, Nagoya, Aichi 453-0053, Japan. ${ }^{4}$ Department of Psychiatry, Tsukuba Psychosomatics Clinic, 5-12-4, Kenkyu-gakuen, Tsukuba, Ibaraki 305-0817, Japan. ${ }^{5}$ Clinical Research Center, Shizuoka Cancer Center, 1007 Shimonagakubo, Nagaizumi, Sunto-gun, Shizuoka 411-8777, Japan. ${ }^{6}$ Information Management Office, Shizuoka Cancer Center, 1007 Shimonagakubo, Nagaizumi, Sunto-gun, Shizuoka 411-8777, Japan.

Received: 2 September 2020 Accepted: 20 January 2021 Published online: 04 February 2021

\section{References}

1. Bray F, Ferlay J, Soerjomataram I, et al. Global cancer statistics 2018: GLOBOCAN estimates of incidence and mortality worldwide for 36 cancers in 185 countries. CA Cancer J Clin. 2018;68:394-424. https://doi.org/10.3322/ caac.21492.

2. Dekker E, Tanis PJ, Vleugels JLA, et al. Colorectal cancer. Lancet. 2019;394: 1467-80. https://doi.org/10.1016/S0140-6736(19)32319-0.

3. NCCN Guidelines colon cancer version 4. 2020, https://www.nccn.org/; Accessed 2 July 2020.

4. Grothey A, Sargent D, Goldberg RM, et al. Survival of patients with advanced colorectal cancer improves with the availability of fluorouracilleucovorin, irinotecan, and oxaliplatin in the course of treatment. J Clin Oncol. 2004;22:1209-14. https://doi.org/10.1200/JCO.2004.11.037.

5. Tournigand C, André T, Achille E, et al. FOLFIRI followed by FOLFOX6 or the reverse sequence in advanced colorectal cancer: a randomized GERCOR study. J Clin Oncol. 2004;22:229-37. https://doi.org/10.1200/JCO.2004.05.113.

6. Colucci G, Gebbia V, Paoletti G, et al. Phase III randomized trial of FOLFIRI versus FOLFOX4 in the treatment of advanced colorectal cancer: a multicenter study of the Gruppo OncologicoDell'Italia Meridionale. J Clin Oncol. 2005;23:4866-75. https://doi.org/10.1200/JCO.2005.07.113.

7. Yamazaki K, Nagase M, Tamagawa $H$, et al. Randomized phase III study of bevacizumab plus FOLFIRI and bevacizumab plus mFOLFOX6 as first-line 
treatment for patients with metastatic colorectal cancer (WJOG4407G). Ann Oncol. 2016;27:1539-46. https://doi.org/10.1093/annonc/mdw206.

8. Field KM, Kosmider S, Jefford M, et al. Chemotherapy treatments for metastatic colorectal cancer: is evidence-basedmedicine in practice? J Oncol Pract. 2008;4:271-6. https://doi.org/10.1200/JOP.0852002.

9. Marschner N, Arnold D, Engel E, et al. Oxaliplatin-based first-line chemotherapy is associated with improved overall survival compared to first-line treatment with irinotecan-based chemotherapy in patients with metastatic colorectal cancer - results from a prospective cohortstudy. Clin Epidemiol. 2015;7:295-303. https://doi.org/10.2147/CLEP.S73857.

10. Liang XB, Hou SH, Li YP, et al. Irinotecan or oxaliplatin combined with 5fluorouracil and leucovorin as first-linetherapy for advanced colorectal cancer: a meta-analysis. Chin Med J. 2010;123:3314-8.

11. Golfinopoulos V, Salanti G, Pavlidis N, et al. Survival and disease-progression benefits with treatment regimens for advanced colorectal cancer: a metaanalysis. Lancet Oncol. 2007;8:898-911. https://doi.org/10.1016/S14702045(07)70281-4

12. Zhuang L, Bai J, Huang $H$, et al. Meta-analysis of chemotherapy with irinotecan or oxaliplatin-involved regimen for untreated metastatic advanced colorectal cancer. Oncol Res. 2010;18:437-44. https://doi.org/10. 3727/096504010x12671222663511.

13. Teng $\mathrm{CL}$, Wang CY, Chen $\mathrm{YH}$, et al. Optimal sequence of irinotecan and oxaliplatin-based regimens in metastatic colorectal cancer: a populationbased observational study. PLoS One. 2015;10:e0135673. https://doi.org/10. 1371/journal.pone.0135673.

14. Cassidy J, Clarke S, Díaz-Rubio E, et al. Randomized phase III study of Capecitabine plus oxaliplatin compared with fluorouracil/folinic acid plus oxaliplatin as first-line therapy for metastatic colorectal cancer. J Clin Oncol. 2008;26:2006-12. https://doi.org/10.1200/JCO.2007.14.9898.

15. Hong YS, Park YS, Lim HY, et al. S-1 plus oxaliplatin versus capecitabine plus oxaliplatin for first-line treatment of patients with metastatic colorectal cancer: a randomised, non-inferiority phase 3 trial. Lancet Oncol. 2012;13: 1125-32. https://doi.org/10.1016/S1470-2045(12)70363-7.

16. Yamada $Y$, Takahari D, Matsumoto $H$, et al. Leucovorin, fluorouracil, and oxaliplatin plus bevacizumab versus S-1 and oxaliplatin plus bevacizumab in patients with metastatic colorectal cancer (SOFT): an open-label, noninferiority, randomised phase 3 trial. Lancet Oncol. 2013;14:1278-86. https:// doi.org/10.1016/S1470-2045(13)70490-X

17. Fuchs CS, Marshall J, Mitchell E, et al. Randomized, controlled trial of irinotecan plus Infusional, bolus, or oral Fluoropyrimidines in first-line treatment of metastatic colorectal cancer: results from the BICC-C study. J Clin Oncol. 2007;25:4779-86. https://doi.org/10.1200/JCO.2007.11.3357.

18. Muro K, Boku N, Shimada Y, et al. Irinotecan plus S-1 (IRIS) versus fluorouracil and folinic acid plus irinotecan (FOLFIRI) as second-line chemotherapy for metastatic colorectal cancer: a randomised phase 2/3 non-inferiority study (FIRIS study). Lancet Oncol. 2010;11:853-60. https://doi. org/10.1016/S1470-2045(10)70181-9

19. Higgins JPT, Thomas J, Chandler J, et al. Cochrane handbook for systematic reviews of interventions. 2nd ed; 2019.

20. Tierney JF, Stewart LA, Ghersi D, et al. Practical methods for incorporating summary time-to-event data into meta-analysis. Trials. 2007;8:16. https://doi. org/10.1186/1745-6215-8-16.

21. Maughan TS, Adams RA, Smith CG, et al. Addition of Cetuximab to Oxaliplatin-based first-line combination chemotherapy for treatment of advanced colorectal cancer: results of the randomised phase 3 MRC COIN trial. Lancet. 2011;377:2103-14. https://doi.org/10.1016/S01406736(11)60613-2

22. Efficacy and safety of xeliri + avastin followed by xelox + avastin or reverse sequence in metastatic colorectal cancer (PASSION), https://clinicaltrials.gov/ ct2/show/NCT02119026. Accessed 2 July 2020.

23. FOLFIRI or FOLFOX with or without cetuximab in patients with metastatic adenocarcinoma of the colon or rectum. https://clinicaltrials.gov/ct2/show/ NCT00077233. Accessed 2 July 2020.

24. IRIS followed by mFOLFOX6 or the reverse sequence in advanced colorectal cancer. https:/clinicaltrials.gov/ct2/show/NCT00316745. Accessed 2 July 2020.

25. Grothey A, Jordan K, Kellner O, et al. Capecitabine plus irinotecan (CAPIRI) vs capecitabine plus oxaliplatin (CAPOX) as first-line therapy of advanced colorectal cancer (ACRC): updated results of a randomized phase II trial. EJC Suppl. 2003;1:S90-1. https://doi.org/10.1016/S1359-6349(03)90328-4.

26. Kalofonos HP, Aravantinos G, Kosmidis $\mathrm{P}$, et al. Irinotecan or oxaliplatin combined with leucovorin and 5-fluorouracil as first-line treatment in advanced colorectal cancer: a multicenter, randomized, phase II study. Ann Oncol. 2005;16:869-77. https://doi.org/10.1093/annonc/mdi193.

27. Comella P, Massidda B, Filippelli G, et al. Oxaliplatin plus high-dose folinic acid and 5-fluorouracil i.v. bolus (OXAFAFU) versus irinotecan plus highdose folinic acid and 5-fluorouracil i.v. bolus (IRIFAFU) in patients with metastatic colorectal carcinoma: a southern Italy cooperative oncology group phase III trial. Ann Oncol. 2005;16:878-86. https://doi.org/10.1093/ annonc/mdi185

28. Feliu J, Castañón C, Salud A, et al. Phase II randomised trial of raltitrexedoxaliplatin vs raltitrexed-irinotecan as first-line treatment in advanced colorectal cancer. Br J Cancer. 2005;93:1230-5. https://doi.org/10.1038/sj.bjc. 6602860 .

29. Zheng $\mathrm{H}$, Chen JZ, Liao WJ, et al. Efficacy of Avastin in combination with irinotecan for metastatic colorectal cancer. Nan Fang Yi Ke Da Xue Xue Bao. 2006:26:689-91.

30. Bajetta E, Di Bartolomeo M, Buzzoni R, et al. Uracil/ftorafur/leucovorin combined with irinotecan (TEGAFIRI) or oxaliplatin (TEGAFOX) as first-line treatment for metastatic colorectal cancer patients: results of randomised phase II study. Br J Cancer. 2007;96:439-44. https://doi.org/10.1038/sj.bjc. 6603493.

31. Seymour MT, Maughan TS, Ledermann JA, et al. Different strategies of sequential and combination chemotherapy for patients with poor prognosis advanced colorectal cancer (MRC FOCUS): a randomised controlled trial. Lancet. 2007;370:143-52. https://doi.org/10.1016/S01406736(07)61087-3.

32. Rosati G, Cordio S, Bordonaro R, et al. Capecitabine in combination with oxaliplatin or irinotecan in elderly patients with advanced colorectal cancer: results of a randomized phase II study. Ann Oncol. 2010;21:781-6. https:// doi.org/10.1093/annonc/mdp359.

33. Ocvirk J, Brodowicz T, Wrba F, et al. Cetuximab plus FOLFOX6 or FOLFIRI in metastatic colorectal cancer: CECOG trial. World J Gastroenterol. 2010;16: 3133-43. https://doi.org/10.3748/wjg.v16.i25.3133.

34. Moosmann N, von Weikersthal LF, Vehling-Kaiser U, et al. Cetuximab plus capecitabine and irinotecan compared with cetuximab plus capecitabine and oxaliplatin as first-line treatment for patients with metastatic colorectal cancer: AlO KRK-0104--a randomized trial of the German AIO CRC study group. J Clin Oncol. 2011;29:1050-8. https://doi.org/10.1200/JCO.2010.31.1936.

35. Schmiegel W, Reinacher-Schick A, Arnold D, et al. Capecitabine/irinotecan or capecitabine/oxaliplatin in combination with bevacizumab is effective and safe as first-line therapy for metastatic colorectal cancer: a randomized phase II study of the AlO colorectal study group. Ann Oncol. 2013;24:15807. https://doi.org/10.1093/annonc/mdt028.

36. Folprecht $\mathrm{G}$, Gruenberger $\mathrm{T}$, Bechstein $\mathrm{W}$, et al. Survival of patients with initially unresectable colorectal liver metastases treated with FOLFOX/ cetuximab or FOLFIRI/cetuximab in a multidisciplinary concept (CELIM study). Ann Oncol. 2014;25:1018-25. https://doi.org/10.1093/annonc/ mdu088.

37. Parikh AR, Lee FC, Yau L, et al. MAVERICC, a randomized, biomarkerstratified, phase II study of mFOLFOX6-Bevacizumab versus FOLFIRIBevacizumab as first-line chemotherapy in metastatic colorectal cancer. Clin Cancer Res. 2019;25:2988-95. https://doi.org/10.1158/1078-0432.CCR-181221.

38. Carrato A, Abad A, Massuti B, et al. First-line panitumumab plus FOLFOX4 or FOLFIRI in colorectal cancer with multiple or unresectable liver metastases: a randomised, phase II trial (PLANET-TTD). Eur J Cancer. 2017;81:191-202. https://doi.org/10.1016/j.ejca.2017.04.024.

39. Yamada Y, Denda T, Gamoh M, et al. S-1 and irinotecan plus bevacizumab versus mFOLFOX6 or CapOX plus bevacizumab as first-line treatment in patients with metastatic colorectal cancer (TRICOLORE): a randomized, open-label, phase III, noninferiority trial. Ann Oncol. 2018;29:624-31. https:// doi.org/10.1093/annonc/mdx816.

40. Nakayama G, Mitsuma A, Sunagawa Y, et al. Randomized phase II trial of CapOX plus Bevacizumab and CapIRI plus Bevacizumab as first-line treatment for Japanese patients with metastatic colorectal cancer (CCOG1201 study). Oncologist. 2018;23:919-27. https://doi.org/10.1634/ theoncologist.2017-0640.

41. Van Cutsem E, Cervantes A, Adam R, et al. ESMO consensus guidelines for the management of patients with metastatic colorectal cancer. Ann Oncol. 2016;27:1386-422. https://doi.org/10.1093/annonc/mdw235.

42. Yoshino T, Arnold D, Taniguchi H, et al. Pan-Asian adapted ESMO consensus guidelines for the management of patients with metastatic colorectal 
cancer: a JSMO-ESMO initiative endorsed by CSCO, KACO, MOS, SSO and TOS. Ann Oncol. 2018:29:44-70. https://doi.org/10.1093/annonc/mdx738.

43. Goldberg RM, Sargent DJ, Morton RF, et al. A randomized controlled trial of fluorouracil plus leucovorin, irinotecan, and oxaliplatin combinations in patients with previously untreated metastatic colorectal cancer. J Clin Oncol. 2004;22:23-30. https://doi.org/10.1200/JCO.2004.09.046.

44. Goldberg RM, Sargent DJ, Morton RF, et al. Randomized controlled trial of reduced-dose bolus fluorouracil plus leucovorin and irinotecan or infused fluorouracil plus leucovorin and oxaliplatin in patients with previously untreated metastatic colorectal cancer: a North American intergroup trial. J Clin Oncol. 2006;24:3347-53. https://doi.org/10.1200/JCO.2006.06.1317.

45. Delaunoit T, Goldberg RM, Sargent DJ, et al. Mortality associated with daily bolus 5 -fluorouracil/leucovorin administered in combination with either irinotecan or oxaliplatin: results from intergroup trial N9741. Cancer. 2004; 101:2170-6. https://doi.org/10.1002/cncr.20594.

46. Johnson KR, Ringland C, Stokes BJ, et al. Response rate or time to progression as predictors of survival in trials of metastatic colorectal cancer or non-small-cell lung cancer: a meta-analysis. Lancet Oncol. 2006;7:741-6. https://doi.org/10.1016/S1470-2045(06)70800-2.

47. Ren T, Wang S, Shen Z, et al. Efficacy and safety of bevacizumab plus oxaliplatin- or irinotecan-based doublet backbone chemotherapy as the first-line treatment of metastatic colorectal cancer: a systematic review and meta-analysis. Drug Saf. 2020. https://doi.org/10.1007/s40264-020-00997-2.

48. Kamiyama H, Takano S, Tsuboi K, et al. Anti-angiogenic effects of SN38 (active metabolite of irinotecan): inhibition of hypoxia-inducible factor 1 alpha (HIF-1alpha)/vascular endothelial growth factor (VEGF) expression of glioma and growth of endothelial cells. J Cancer Res Clin Oncol. 2005;131: 205-13. https://doi.org/10.1007/s00432-004-0642-z.

49. Murono K, Tsuno NH, Kawai K, et al. SN-38 overcomes chemoresistance of colorectal cancer cells induced by hypoxia, through HIF1alpha. Anticancer Res. 2012;32:865-72.

50. Yoshino T, Yamanaka T, Oki E, et al. Efficacy and long-term peripheral sensory neuropathy of 3 vs 6 months of oxaliplatin-based adjuvant chemotherapy for colon cancer: the ACHIEVE phase 3 randomized clinical trial. JAMA Oncol. 2019;5:1574-81. https://doi.org/10.1001/jamaoncol.2019. 2572.

51. Aderka D, Stintzing S, Heinemann V. Explaining the unexplainable: discrepancies in results from the CALGB/SWOG 80405 and FIRE-3 studies. Lancet Oncol. 2019;20:e274-83. https://doi.org/10.1016/S14702045(19)30172-X

52. Fujita $\mathrm{Y}$, Taguri $\mathrm{M}$, Yamazaki $\mathrm{K}$, et al. aCGH analysis of predictive biomarkers for response to bevacizumab plus oxaliplatin- or irinotecan-based chemotherapy in patients with metastatic colorectal cancer. Oncologist. 2019;24:327-37. https://doi.org/10.1634/theoncologist.2018-0119.

\section{Publisher's Note}

Springer Nature remains neutral with regard to jurisdictional claims in published maps and institutional affiliations.

Ready to submit your research? Choose BMC and benefit from:

- fast, convenient online submission

- thorough peer review by experienced researchers in your field

- rapid publication on acceptance

- support for research data, including large and complex data types

- gold Open Access which fosters wider collaboration and increased citations

- maximum visibility for your research: over $100 \mathrm{M}$ website views per year

At $\mathrm{BMC}$, research is always in progress.

Learn more biomedcentral.com/submissions 